\title{
DEVELOPMENT OF A WATER ENVIRONMENT FATIGUE DESIGN CURVE FOR AUSTENITIC STAINLESS STEELS
}

\author{
T. R. Leax
}

\section{NOTICE}

This report was prepared as an account of work sponsored by an agency of the United States Government. Neither the United States Government nor any agency thereof, nor any of their employees, nor any of their contractors, subcontractors or their employees, makes any warranty, express or implied, or assumes any legal liability or responsibility for the accuracy, completeness, or any third party's use or the results of such use of any information, apparatus, product, or process disclosed, or represents that its use would not infringe privately owned rights. Reference herein to any specific commercial product, process, or service by trade name, trademark, manufacturer, or otherwise, does not necessarily constitute or imply its endorsement, recommendation, or favoring by the United States Government or any agency thereof or its contractors or subcontractors. The views and opinions of authors expressed herein do not necessarily state or reflect those of the United States Government or any agency thereof. 


\title{
Development of a Water Environment Fatigue Design Curve for Austenitic Stainless Steels
}

\author{
T. R. Leax \\ Bechtel Bettis, Inc. \\ West Mifflin, PA 15122
}

\section{Introduction}

This note presents the technical basis for a proposed strain-rate and temperature independent fatigue design curve for austenitic stainless steels.

\section{Statistical Model}

Fatigue data on austenitic stainless steels in LWR environments were obtained from References 1-15. Data obtained from sensitized material and tested in high oxygen water were excluded from the database. The remaining fatigue data (383 failure points) were fit to the following empirical model using nonlinear least squares:

$$
N_{f}=A \cdot\left(\varepsilon_{S W T}-\varepsilon_{0}\right)^{b} \cdot\left[P+(1-P) \cdot \exp \left(-k Z^{m}\right)\right]
$$

where: $N_{f}$ is cycles to failure

$A=1.185 \times 10^{-2}$ for wrought steels (other than316NG) in PWR water

$A=3.313 \times 10^{-2}$ for wrought steels (other than 316NG) in BWR water

$A=1.876 \times 10^{-2}$ for wrought 316NG in PWR water

$A=5.247 \times 10^{-2}$ for wrought 316NG in BWR water

$A=2.203 \times 10^{-2}$ for welds in PWR water

$A=6.161 \times 10^{-2}$ for welds in BWR water

$A=1.870 \times 10^{-2}$ for castings in PWR water

$A=5.229 \times 10^{-2}$ for castings in BWR water

$\varepsilon_{S W T}=\varepsilon_{a}^{0.7}\left(\sigma_{\max } / E\right)^{0.3} \quad$ (modified Smith-Watson Topper parameter)

$\varepsilon_{a}$ is the strain amplitude (in/in)

$\sigma_{\max }$ is the maximum stress in the cycle (ksi)

$E$ is the elastic modulus (ksi)

$\varepsilon_{0}=9.068 \times 10^{-4}$

$b=-2.097$

$P=0.109$ for wrought steels and welds

$P=0.0286$ for cast steels

$k=149.0$ in PWR water

$k=383.7 \quad$ in BWR water

$Z=\dot{\varepsilon} \exp (Q / R T) \quad$ (Zener-Hollomon parameter)

$\dot{\varepsilon}$ is the strain rate (in/in/s) 
$Q=35,170 \mathrm{cal} / \mathrm{mol}$

$T$ is the absolute temperature $(\mathrm{K})$

$R$ is the gas constant $(1.987 \mathrm{cal} / \mathrm{mol}-\mathrm{K})$

$m=-0.2233$

A plot comparing the observed and predicted cycles to failure is shown in Figure 1. Predicted lives were generally within a factor of two of the measured fatigue life. Figure 2 shows a plot of the residuals (i.e., the difference between the observed and predicted values) versus the predicted fatigue life. As shown in this plot, there is no systematic variation of the residuals with predicted life. Further, the assumption of constant variance with fatigue life inherent in least squares estimation is validated. Figures 3-6 show plots of the residuals versus the independent variables (e.g., temperature, strain rate, etc.). As shown in these plots, there is no significant systematic bias in the residuals with changes in any of the independent variables.

In developing the model, data scatter was not assumed constant with fatigue life, but instead was assumed to change (increase) with increasing fatigue life. The increasing data scatter with fatigue life was modeled using the Box-Cox transformation (Reference 16). The variation in data scatter with fatigue life determined from the data is shown in Figure 7. Data scatter, defined as the difference between the median curve and the $5 \%$ one-sided lower prediction limit, varies from a factor on approximately 1.4 on life at a median fatigue life of ten cycles to a factor of approximately 2.4 on life at a median fatigue life of $10^{7}$ cycles.

\section{Development of Lower Bound, Mean Stress Corrected Fatigue Curve}

Since calculating the temperature and strain rate in any given transient is difficult, a lower bound curve applicable to all transients was developed from Equation (1) assuming a temperature of $600^{\circ} \mathrm{F}$ and a strain rate of $10^{-6} \mathrm{in} / \mathrm{in} / \mathrm{s}$. This temperature and strain rate is expected to provide conservative fatigue life predictions for the vast majority of transients. The choices made for these parameters are discussed in the next section. The proposed curve was developed assuming wrought material behavior in low oxygen water and is appropriate for use in the design of pressure vessel and piping components. Examination of Equation (1) indicates that welded stainless steel is expected to provide longer fatigue lives for a given stress and strain amplitude. Cast stainless steel also provides better fatigue performance, except at high temperatures and very low strain rates. Consequently, assuming wrought material behavior is conservative for both welded and cast austenitic stainless steels. Equation (1) predicts that the fatigue strength in high oxygen (BWR) water is slightly better than in low oxygen (PWR) water and so assuming a low oxygen water environment is also conservative.

The Smith-Watson-Topper (SWT) parameter was used in correcting for the maximum effect of mean stress. The ASME Boiler \& Pressure Vessel Code Criteria Document (Reference 17) recommends use of either the modified Goodman approach or the Peterson cubic equation method for mean stress adjustment of the fatigue curve. However, the SWT parameter was used instead for the reasons discussed in References 18 and 19. The exponents in the SWT parameter (i.e., 0.3 and 0.7 in Equation (1)) were determined from tests, in air, performed using both zero and positive mean strains. In correcting for the maximum effect of mean stress, the maximum stress was constrained to be at least equal to the cyclic yield strength $(38 \mathrm{ksi})$ at $600^{\circ} \mathrm{F}$ for a strain rate of $10^{-6}$ in/in/s. 
The stress amplitude (ksi) can be estimated from the following equation:

$$
\sigma_{\mathrm{a}}=\sigma_{0}+\mathrm{A}_{0} \varepsilon_{\mathrm{a}}^{n}
$$

where: $\quad \sigma_{0}=23.86 \mathrm{e}^{(-0.03113 T)}$

$\mathrm{T}$ is the temperature $\left({ }^{\circ} \mathrm{F}\right)$

$$
\begin{aligned}
& A_{0}=2566 e^{\left(-\left(1.407 \times 10^{-3}+3.027 \times 10^{-4} \dot{\varepsilon}\right) T\right)} \\
& n=0.9182
\end{aligned}
$$

The effect of the mean stress correction on the lower bound curve is shown in Figure 8. At $10^{6}$ cycles, the correction is less than a factor of $20 \%$ on the strain amplitude.

\section{Design Curve Development}

For application to design of nuclear power plant components, it is difficult to accurately establish operating temperature and strain-rate conditions for every anticipated and unanticipated operating transient in a given plant. Coupled with the ASME B\&PV Section III (NB-3222.4(e)(5)) requirement to superimpose stress cycles of various origins that produce a total stress difference range greater than the stress ranges of the individual cycles makes it very desirable to have temperature and strain rate independent fatigue curves.

For these reasons, fatigue design curves are developed for the conditions of $600^{\circ} \mathrm{F}$ and low strain rate $\left(10^{-6} \mathrm{in} / \mathrm{in} / \mathrm{s}\right)$. These assumptions are somewhat arbitrary but are judged to reasonably account for temperature and strain rate effects in the design stages of Section III components. The benefits of this approach are a simpler design procedure and a plant that is not strain-rate dependent and can be safely operated within the temperature range applicable to ASME B\&PV Section III construction.

Using these assumed conditions, the fatigue data are compared to the lower bound curve in Figure 9. All the data at low strain amplitudes are from tests at relatively high strain rates, whereas the lower bound curve shown in the figures is for a low strain rate $\left(10^{-6}\right.$ $\mathrm{in} / \mathrm{in} / \mathrm{s})$. The large apparent margin at low strain amplitudes is due to the lack of data at both low strain amplitudes and low strain rates. The Equation (1) model assumes that the effect of water environments is the same at both high and low strain amplitudes.

\section{Proposed Design Curve}

A proposed fatigue design curve was developed from the lower bound curve by applying a factor of five on cycles. The factor of five on cycles is meant to account for surface finish, size effects, and variable amplitude loading effects (the effects of water environment and data scatter are already accounted for by the lower bound curve). The proposed design curve is compared to the current ASME design curve in the table below and in Figure 10. 


\begin{tabular}{|r|c|c||}
\hline \multicolumn{1}{|c|}{ Cycles } & $\begin{array}{c}\text { Stress } \\
\text { Amplitude (ksi) }\end{array}$ & ASME (ksi) \\
\hline 10 & 276 & 708 \\
\hline 20 & 199 & 512 \\
\hline 50 & 132 & 345 \\
\hline 100 & 98.5 & 261 \\
\hline 200 & 72.5 & 201 \\
\hline 500 & 51.5 & 148 \\
\hline 1000 & 41.7 & 119 \\
\hline 2000 & 35.2 & 97 \\
\hline 5000 & 29.7 & 76 \\
\hline 10000 & 27.0 & 64 \\
\hline 20000 & 25.1 & 55.5 \\
\hline 50000 & 23.5 & 46.3 \\
\hline 100000 & 22.7 & 40.8 \\
\hline 200000 & 22.1 & 35.9 \\
\hline 500000 & 21.6 & 31.0 \\
\hline 100000 & 21.4 & 28.3 \\
\hline \multicolumn{3}{|l}{} \\
\hline
\end{tabular}

\section{$\underline{\text { References }}$}

1. O. K. Chopra and D. J. Gavenda, "Effects of LWR Coolant Environments on Fatigue Lives of Austenitic Stainless Steels", PVP Vol. 353, ASME, 1997, pp. 87-97

2. K. lida, J. Fukakura, M. Higuchi, H. Kobayashi, S. Miyazono and M. Nakao, "Abstract of DBA Committee Report, 1988 - Survey of Fatigue Strength Data of Nuclear Structural Materials in Japan"

3. M. Higuchi and K. lida, "Reduction in Low-Cycle Fatigue Life of Austenitic Stainless Steels in High-Temperature Water", ASME, 1997, pp. 79-85

4. H. Kanaski, "Fatigue Life of Stainless Steels and Alloy 600 in PWR Primary Water", presented at the Pressure Vessel Research Council Meeting, October 7-9, 1996, Columbus, $\mathrm{OH}$

5. M. Fujiwara, T. Endo and H. Kanaski, "Strain Rate Effects on the Low Cycle Fatigue Strength of 304 Stainless Steel in High Temperature Water Environment", ASM, .Metals Park, OH, 1986, pp. 309-313

6. O. K. Chopra and J. L. Smith, "Estimation of Fatigue Strain-Life Curves for Austenitic Stainless Steels in Light Water Reactor Environments", PVP Vol. 374, ASME, 1998, pp. 249-259

7. O. K. Chopra, H. M. Chung, E. E. Gruber, T. F. Kassner, W. E. Rather, W. J. Shack, J. L. Smith, W. K. Soppet and R. V. Strain, NUREG/CR-4667, Vol. 26, ANL-98/30, March 1999

8. O. K. Chopra, "Effects of LWR Coolant Environments on Fatigue Design Curves of Austenitic Stainless Steels", NUREG/CR-5704, April 1999 
9. "Effects of Strain Rate and Temperature Change on the Fatigue Life of Stainless Steel in PWR Primary Water", Welding Research Council Progress Reports, Vol. LII, No. 3/4, March/April 1997, pp. 66-74

10. O. K. Chopra and W. J. Shack, "Fatigue Crack Initiation in LWR Environments", presented at the 1999 IGG-EAC Meeting May 16-21, 1999, held in Turku, Finland

11. JNUFAD (1994)

12. O. K. Chopra \& W. J. Shack, "Environmental Effects on Fatigue Crack Initiation in Piping \& Pressure Vessel Steels", NUREG/CR-6717, May 2001

13. M. Higuchi, K. lida, \& K. Sakaguchi, "Effects of Strain Rate Fluctuation and Strain Holding on Fatigue Life Reduction for LWR Structural Steels in Simulated LWR Water", PVP Vol. 419, 2001, pp.143-152

14. K. Tsutsumi et al, "Fatigue Life Reduction in PWR Water Environment for Stainless Steels", PVP Vol. 410-2, ASME, 2000

15. O. K. Chopra, "Mechanism of Fatigue Crack Initiation in Austenitic Stainless Steels in LWR Environments", paper to be presented at the 2002 PVP Conference, Aug. 4-8, 2002

16. G. E. P. Box and D. R. Cox, "An Analysis of Transformations", Journal of the Royal Statistical Society, Series B 26, 1964, pp. 211-246

17. Criteria of the ASME Boiler \& Pressure Vessel Code for Design by Analysis in Sections III \& VII, Division 2, ASME, 1969

18. G. L. Wire, T. R. Leax and J. T. Kandra, "Mean Stress and Environmental Effects on Fatigue in Type 304 Stainless Steel", PVP Vol. 386, ASME 1999, p. 213

19. N. E. Dowling and S. Thangjitham, "An Overview and Discussion of Basic Methodology for Fatigue”, ASTM STP 1389, ASTM 2000, pp. 3-36 


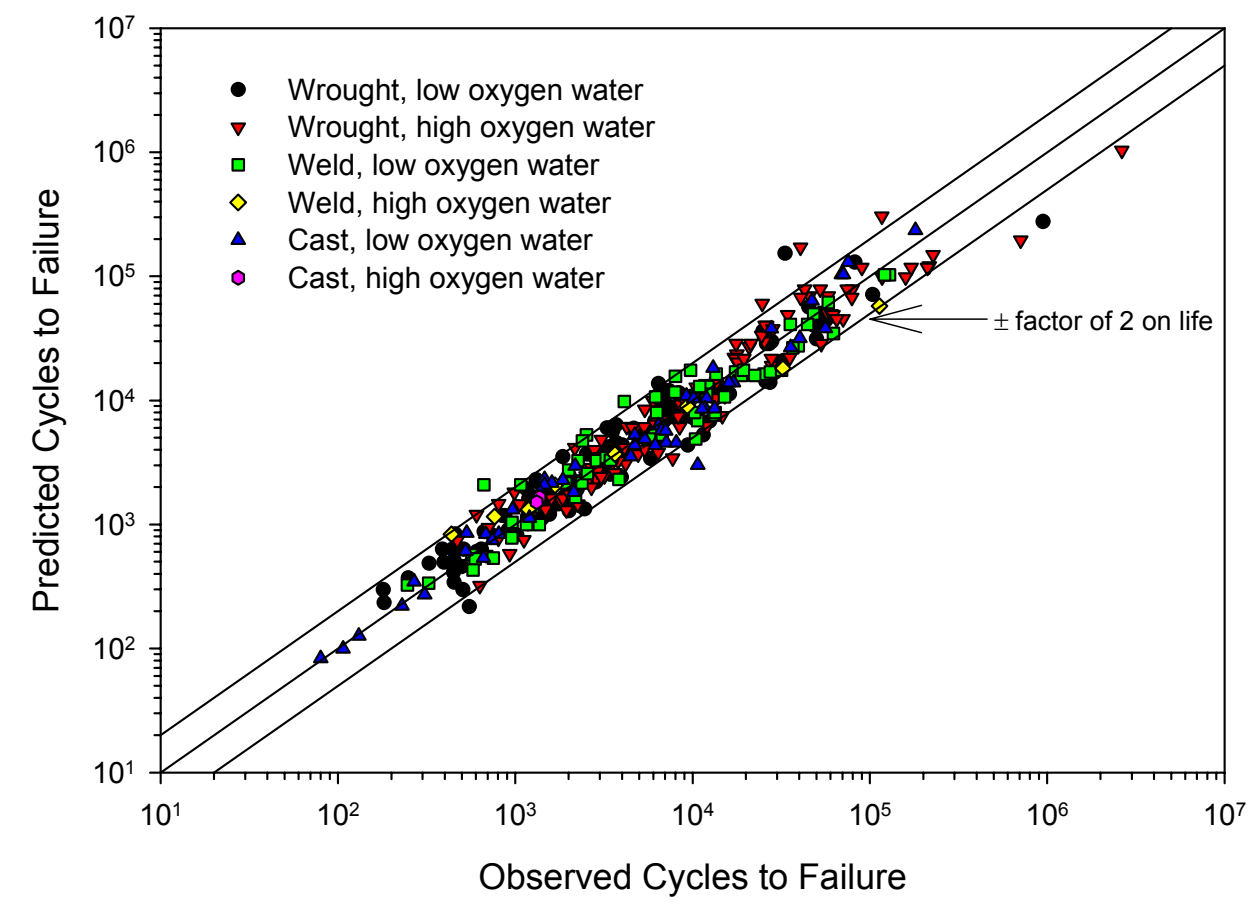

Figure 1 Observed versus predicted cycles to failure.

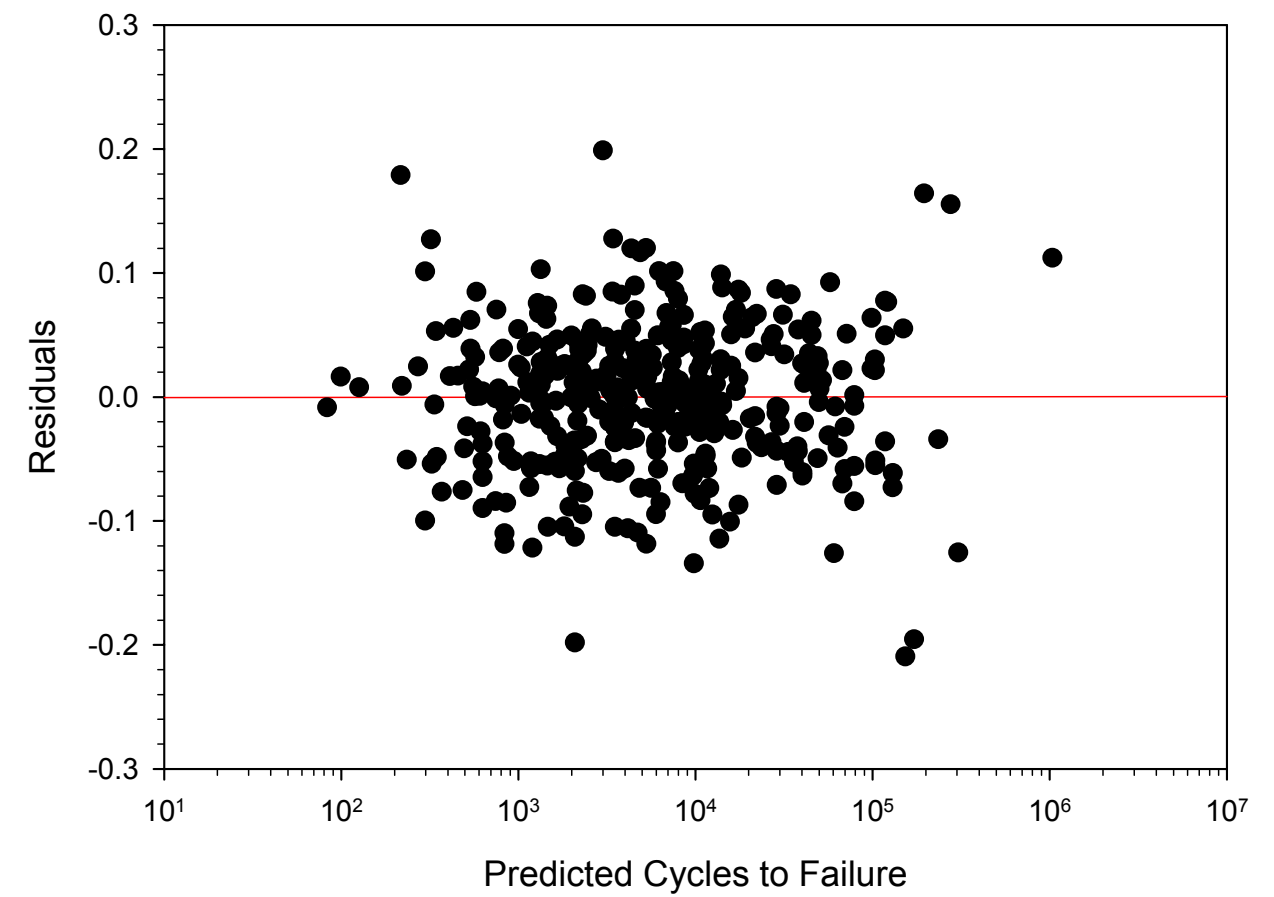

Figure 2 Residuals versus predicted fatigue life. The best-fit line to the data is shown. 


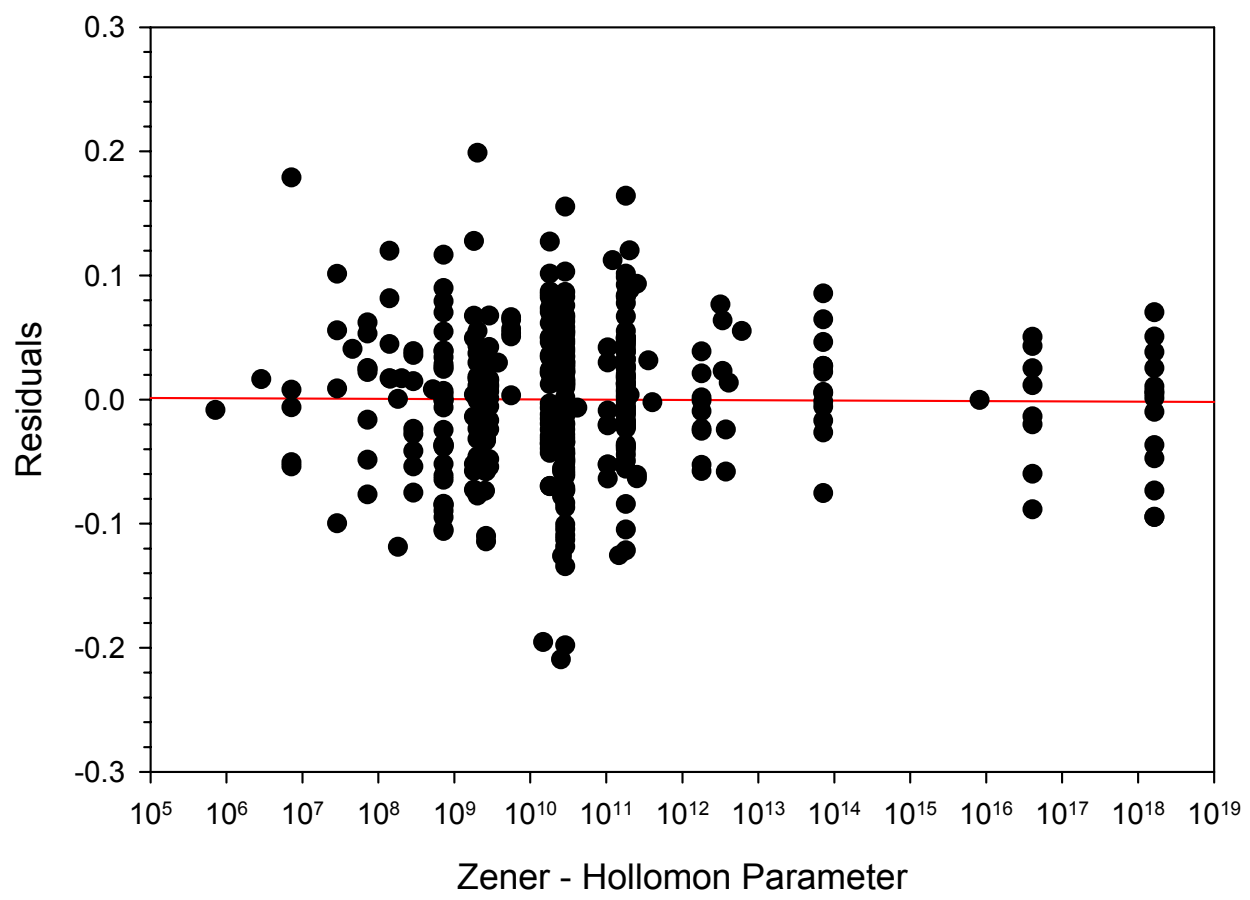

Figure 3 Residuals versus the Zener-Hollomon parameter. The best-fit line to the data is shown.

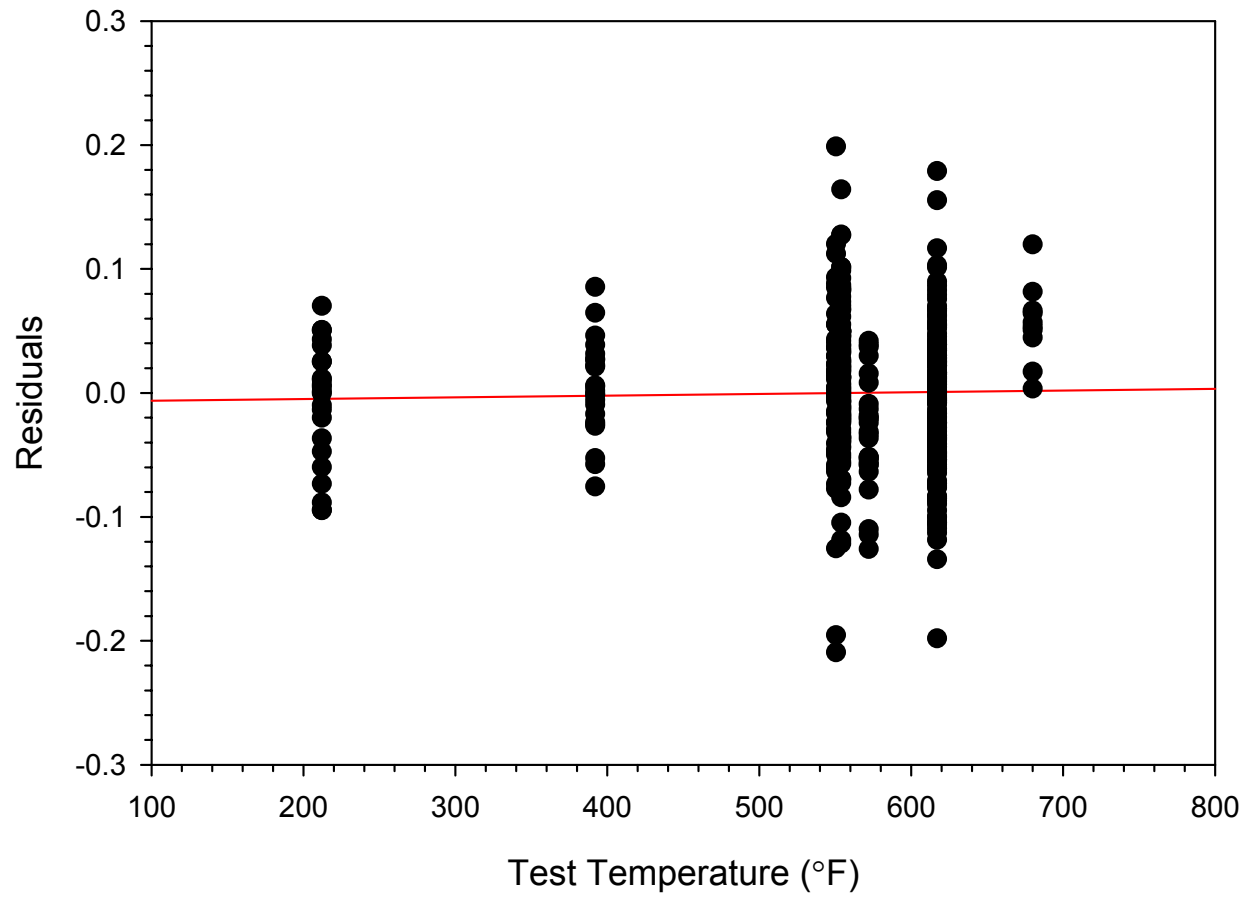

Figure 4 Residuals versus test temperature. The best-fit line to the data is shown. 


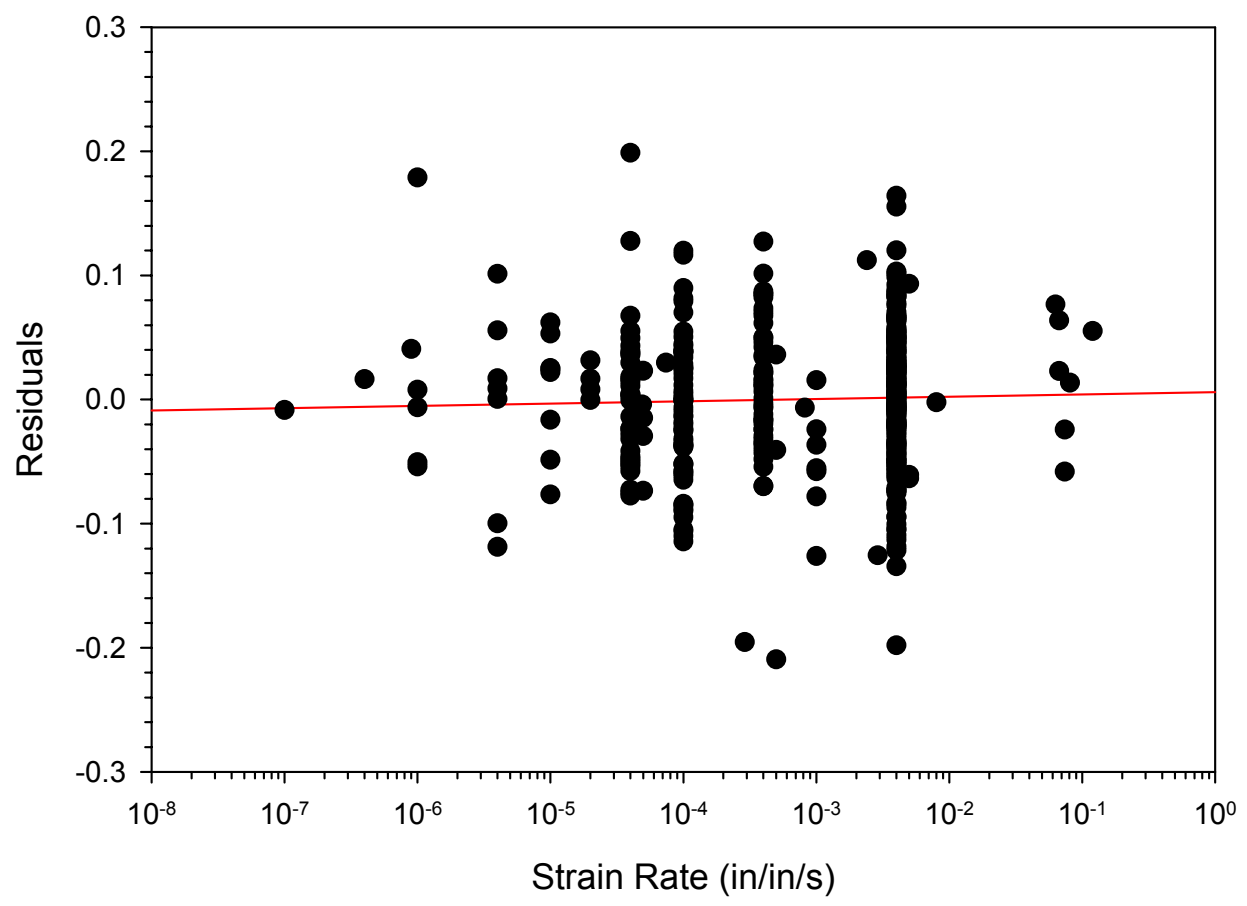

Figure 5 Residuals versus strain rate. The best-fit line to the data is shown.

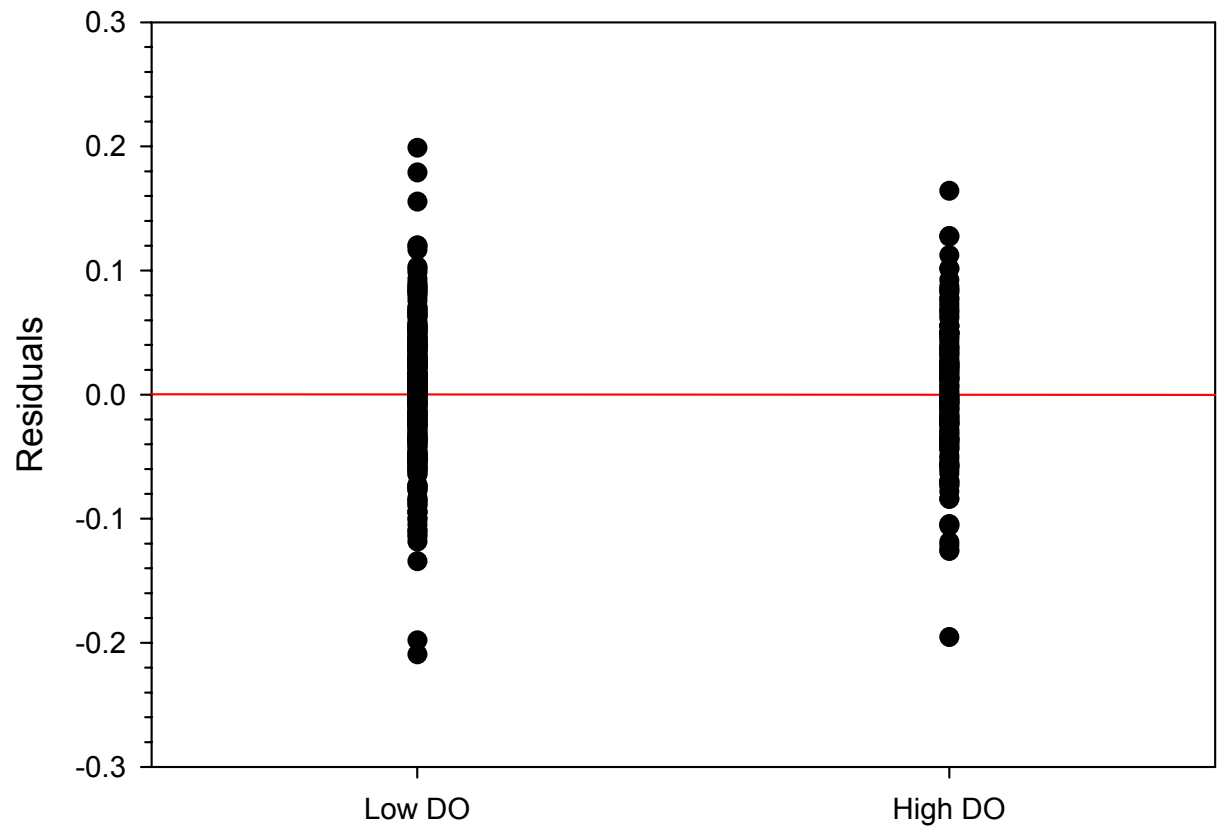

Figure 6 Residuals versus water oxygen level. The best-fit line to the data is shown. 


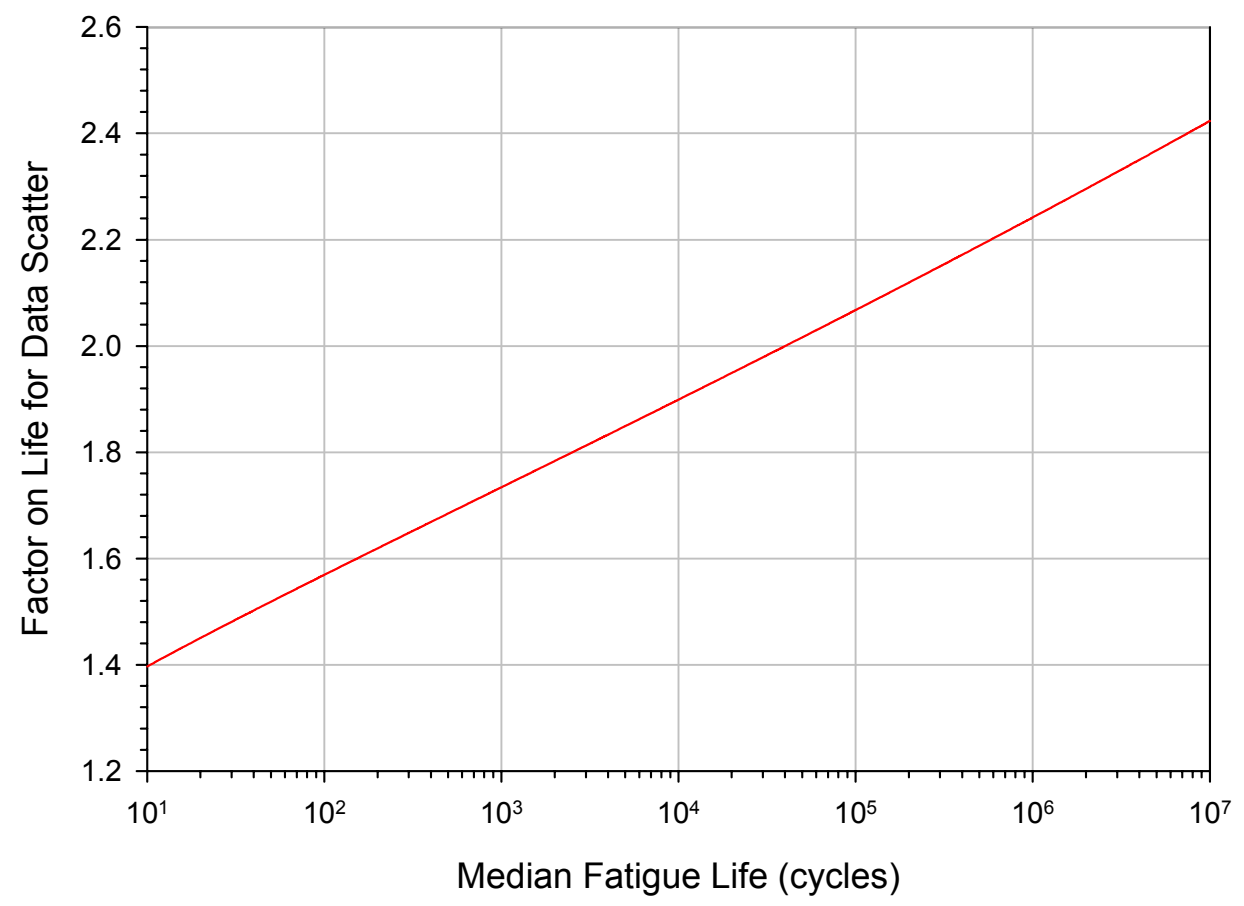

Figure 7 Factor on life needed to account for data scatter (i.e., the difference between the median and lower bound curve).

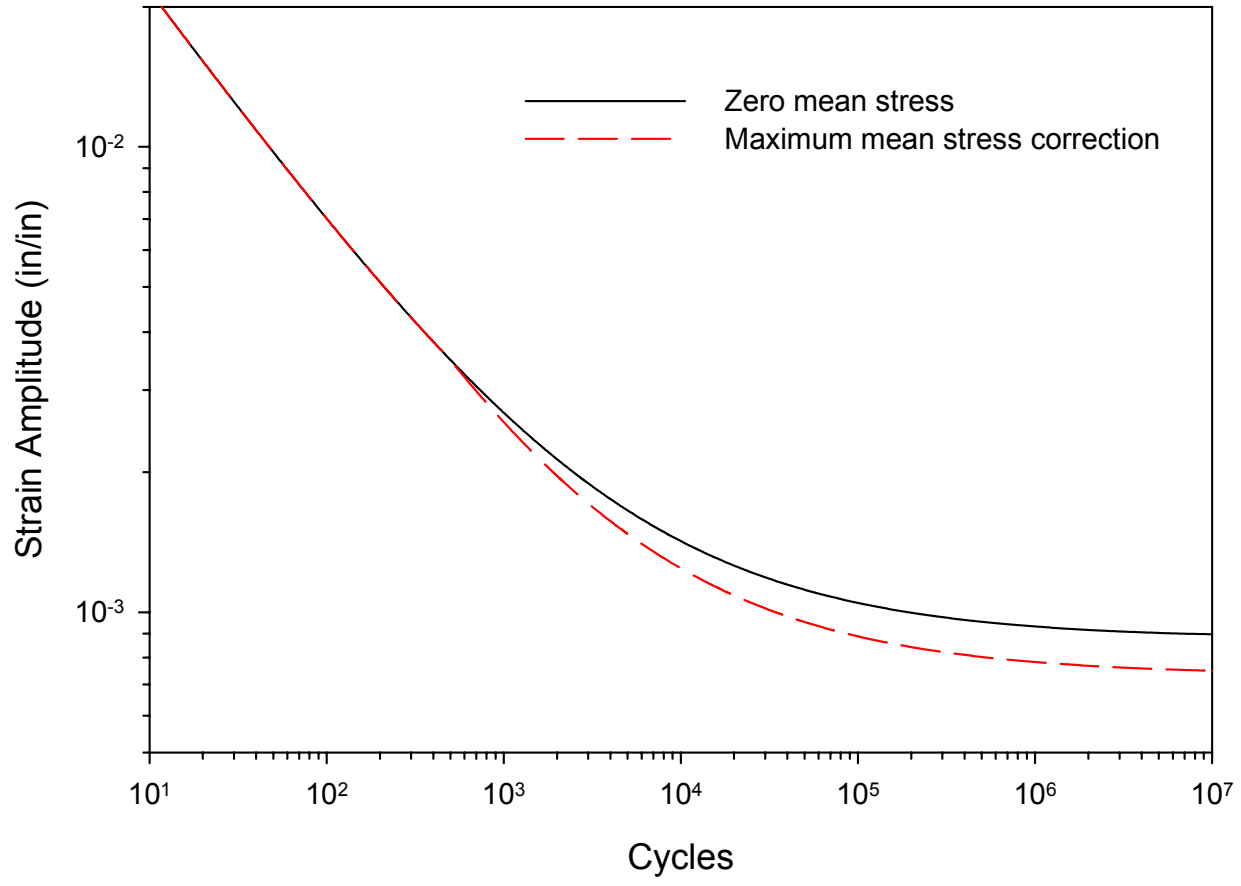

Figure 8 Lower bound curves for wrought steels in low oxygen water at $600^{\circ} \mathrm{F}$ and a strain rate of $10^{-6} \mathrm{~s}^{-1}$. 


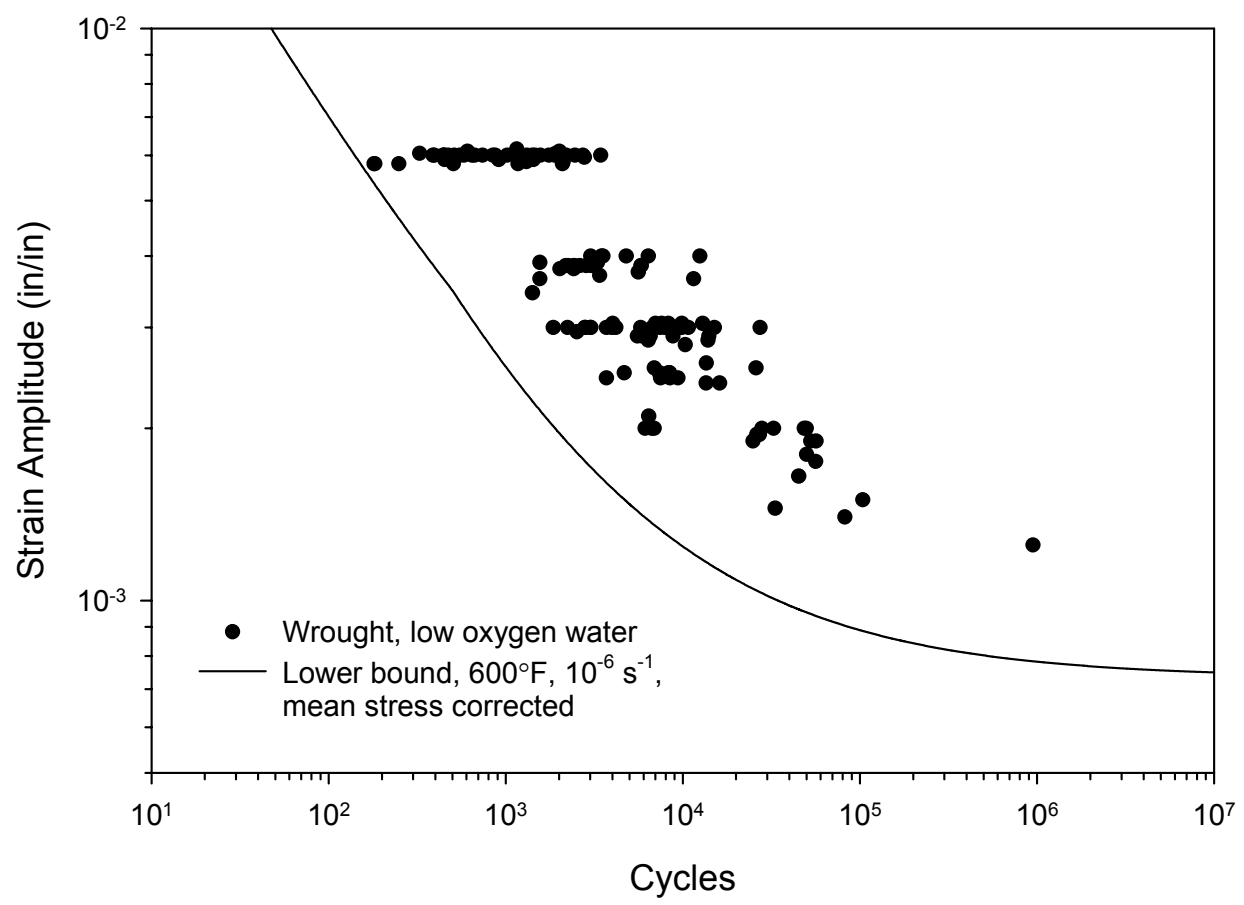

Figure 9 Fatigue data on wrought steels in low oxygen water compared to the lower bound $\left(600^{\circ} \mathrm{F}, 10^{-6} \mathrm{~s}^{-1}\right)$ curve.

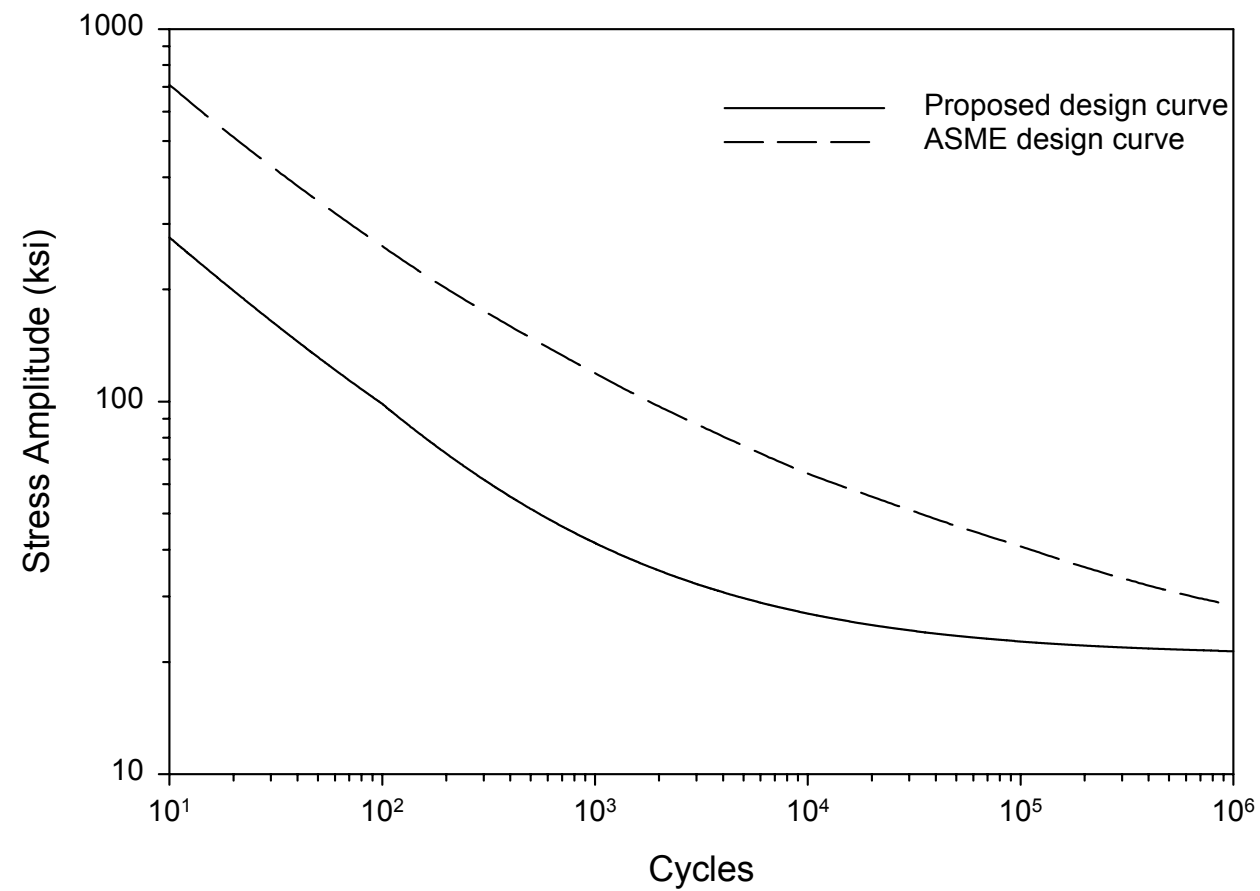

Figure 10 Comparison of the potential design curve to the ASME design curve. 